\title{
Study on Behavior Value Analysis and Decision Methodology of Grid Corporations in China
}

\author{
Yuanbin Jiang ${ }^{1}$ and Ruobing Shuai ${ }^{2}$ \\ ${ }^{1}$ State Grid Chengdu Power Supply Company, Chengdu 610000, China \\ ${ }^{2}$ Guangdong Power Grid Corporation Foshan Power Supply Bureau, Foshan 528000, China \\ Corresponding author: jybthebest@sina.com
}

\begin{abstract}
Based on grid corporations, business environment and value characteristics in China, the article analyzes its behavior value factors, and then divides its behavior into three categories: the behavior only affecting the current Economic Value Added(EVA), the behavior affecting both the current and future EVA, and the behavior only affecting future EVA. Finally, the article studies such corporations, behavior value decision making based upon analyses and classifications above.
\end{abstract}

KeyWords. Value-Based Management(VBM), Economic Value Added(EVA), Behavior Value Factor Behavior, Value Decision Methodology.

\section{Instruction}

Early this century, the idea of Value-based Management(VBM) and EVA was introduced into China from the United States. In 2010, the State-owned Assets Supervision and Administration Commission of the State Council(SASAC) has begun to evaluate the performance of all state-owned enterprises(SOEs) with EVA system, and opened a new era different from the tradition simply focusing on the enterprise scale and profit. In China, with the development of SOEs, introducing EVA is to help SOEs accomplish strategic objectives, improve management mode, and solve problems economically and efficiently.

As significant parts of SOEs, grid corporations construct and operate power grids as the core business, to provide safer, cleaner, and more economic and sustainable power supply. These corporations target at creating sustainable growth in EVA under VBM, in planning, forecasting, evaluation and other enterprise behaviors. Therefore, it is necessary to establish a set of behavior value analysis system for grid corporations in China.

\section{Behavior value factors analysis of grid corporations}

Behavioral value factors analysis refers to factors affecting value inflow and outflow within the enterprise (value added and impairment), thus assessing various enterprise behavior qualitatively and quantitatively. According to the influence on EVA, we can divide enterprise behavior into three categories: the behavior only affecting the current Economic Value Added(EVA), the behavior affecting both the current and future EVA, and the behavior only affecting future EVA, as the Figure shown below: 


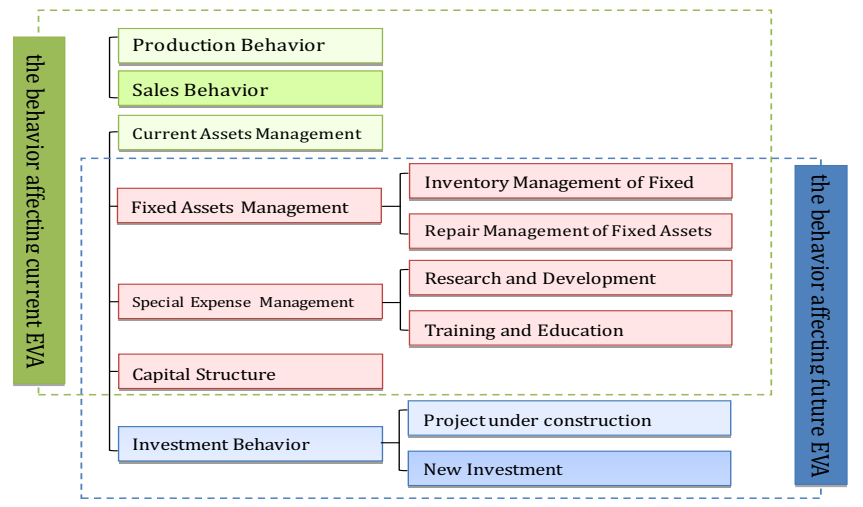

Fig.1. Enterprise behavior classification based on long-term value.

\section{Behavior value decision method of grid corporations}

Grid corporations should establish a set of behavior control system targeting at sustainable EVA growth. The system can clarify the value contribution of the management and the staff respectively to the enterprise, check whether the decision-making deviates from the VBM target, and guide the direction of corporate behavior. Corresponding with the behavior value factors, the behavior value decision method of grid corporations consist of three aspects: the behavior value decision method affecting the current EVA only, both the current and future EVA, and the future EVA only.

\subsection{The behavior value decision method affecting the current EVA only}

Specifically, it is made up of decision methods of income management, cost management, current assets management.

The behavior value decision method of income management. The business process of electricity purchasing (Electricity Sales Income) reflects the company's operating scale and industry status, determined by electricity sales, electricity sales structure, the average unit price of selling. After the decomposition of revenue drivers, we can find associated indicators supporting that. The management can analyze the existing revenue through these indicators under VBM.

\subsection{The behavior value decision method of cost management}

\subsubsection{Electricity purchasing cost}

The business processes of purchasing and selling electricity determine the gross profit level jointly. In terms of electricity purchasing cost analysis, we keep eyes on the quantity and unit price of purchasing electricity from different power suppliers. Doing such analysis is to clarify the impact of electricity purchasing structure and unit price on the electricity purchasing cost. After the decomposition of cost drivers, we can find associated indicators supporting that. The management can analyze the existing cost through these indicators under VBM [1].

\subsubsection{Electricity transmission and distribution cost}

Transmission and distribution cost is the transportation and power grid enterprises to provide electrical energy costs that occurred in the transmission and distribution sectors. It includes the cost of fixed assets and grid operating costs.

\subsubsection{Other costs}


Other costs of grid corporations are costs that not directly related to the volume of business, including office expenses, travel, utilities, and vehicle usage fees. These costs result in an outflow of economic benefits and an reduction in EVA index directly. However, these costs are necessary to maintain the regular operation of company, naturally helping the current inflow of economic benefits. Therefore, we cannot conclude that it is of no value, and the company should carefully control such costs in the manner of quota management.

\subsection{The behavior value decision method of current assets management}

Current assets include cash and cash equivalents, inventory and accounts receivable, etc., belonging to the scope of the overall enterprise value stream. The quota management system is a good option for current assets, analyzing its specific behavior under VBM. It can determine the amount of current assets held by the best, strengthen the turnover, and improve the utilization efficiency [2].

\subsubsection{Cash and cash equivalents management}

Companies hold cash and cash equivalents for three needs: transactional demand, cautious demand and speculative demand. Under the premise of guaranteeing regular operation, stronger cash management can make full use of surplus cash to capture potential investment opportunities.

Obviously, the following question is how to determine the best cash holding. In theory, there are three modes: cost analysis model, inventory model and random model.

1) Cost analysis model suggests that the cost of holding cash includes opportunity cost, management cost and shortage cost. The opportunity cost is directly proportional to the amount of cash holdings. There is no significant relationship between the management cost and cash holdings (given that certain cash holdings are relatively unchanged). The shortage cost is inversely proportional to the amount of cash holdings. Therefore, there is optimal cash holding, minimizing the sum of the three kinds of cost.

2) Inventory model suggests that holding cash incurs opportunity cost (positive with holding cash) and transaction cost (negative with holding cash). The minimization of these two is the optimal amount of cash holding for companies.

3) Random model suggests that the cash demand is difficult to predict, the management determine the lower and upper of cash holding based on experience. When the cash demand exceeds the upper limit, the management converts securities into cash to make up for the insufficiency; when the cash demand is lower than the lower limit, the management investment securities for better return.

\subsubsection{Inventory management}

Inventory is a necessary part to maintain the regular operation of grid corporations, generally including spare parts for repairing, low-value consumptions and so on.

Under VBM, inventory management can be analyzed in three aspects: the claim management system for existing inventories, the utilization efficiency of inventories in need, and the reserve quota.

1) The claim management system should be used for existing inventories. The management ought to claim inventories in details, and distinguish the inventories really needed from others, dealing with unnecessary ones in time.

2) In terms of the utilization efficiency of inventories needed, the management targets at the turnover ratio, checking whether the liquidity and the fund occupied is sensible. Along with the actual usage, the quantities of inventories need to buy can be decided at reasonable levels.

3) Given the maintenance of normal operation, the reserve quota is the economic order quantity. With the change of order quantity, ordering cost and storage cost shift. Economic order quantity is the quantity with the lowest sum of storage cost and ordering cost in a certain period [3]. 


\section{Total cost $=$ Ordering cost + Storage cost}

The economic order quantity is the quantity that makes the total of these two kinds of cost minimum, as the formula expressed:

$$
T C=\frac{Q}{2} \times C+\frac{A}{Q} \times F
$$

TC: the total cost of inventories

Q; the economic order quantity

C: the unit inventory storage cost

A: the total inventories in demand

F: the inventory ordering cost per time

\subsubsection{Account Receivable Management}

In terms of consumer classification differentiated pricing, the power supply can be divided into large industrial electricity, general industrial electricity, commercial electricity, agricultural electricity and residential electricity. Among them, the residential electricity users pay in advance, and it does not incur accounts receivable. While other categories of electricity users, there are sales on credit resulting in accounts receivable. It weakens the current assets turnover, thus impacting on EVA.

Based on accounts aging, the management should implement the responsibility system for corresponding accounts receivable recovery departments, and evaluate such departments in quota control and the reclaim speed. The quota control of accounts receivable can accelerate capital returns and reduce current assets occupancy. Meanwhile, enhancing the recovery rate can improve accounts receivable turnover. Both of them make a contribution to EVA increase directly. According to the control of quota and turnover, the budget of accounts receivable can be reasonable made for next period.

\subsection{The behavior value decision method affecting both the current and future EVA}

\subsubsection{Analysis and decision methods}

For the analysis and decision method of behaviors affecting both the current and future EVA, there are basically two methods: the quantitative evaluation method (formula method) for quantifiable project; the expert evaluation method for un-quantifiable project.

1) The quantitative evaluation method (formula method)

Quantitative evaluation method is to calculate the economic benefits generated and costs and expenses incurred for specific enterprise behavior in each accounting period, thus estimating its impact on EVA for different periods and discounting it with reasonable rate. If the present value of EVA is greater than the cost, such spending is valuable. On the contrary, it damages the enterprise value. This method is suitable for the management of existing fixed assets and its overhaul, which is quantifiable. The formula for calculating the present value of EVA is:

$$
V(X)=\sum_{i=1}^{n}\left\{\left[\left(R-C_{1}\right)-T C_{1} \times W A C C_{1}\right] /(1+r)^{n}\right\}
$$

$V(X)$ : the contribution value of project $X$

$R$ : expected growth in sales resulting from project $X$

$\mathrm{C}_{1}$ : the cost of the project $X$ incurred this period 
$r:$ the discount rate of $E V A$

$n$ : the expected effective years

Expert evaluation method is suitable for un-quantifiable behavior, such as R\&D expense. Expert evaluation method, based on qualitative analysis, uses scoring and other techniques to make a comprehensive evaluation of the results with mathematical statistic characteristics. Such method focuses on experts' experience and opinion determining the weight of each index, and obtains satisfying results with constant feedback and modification. Specific steps are as follows [4]:

The first step is choosing 9 15 experts with both rich practical experience and solid theoretical foundation.

The second step is to determine $\mathrm{n}$ indicators, and then ask selected experts to give independent weight values of each indicator under certain rules.

The third step is to select the results, calculate the mean and standard deviations of each index weight, and check whether to re-determine the weight.

The fourth step is to repeat the third step until the difference between index weight and its average does not exceed the pre-specified criteria, which means the experts' opinions are basically converging. The average index weight with constant modified is what the management wants.

\subsubsection{Existing fixed assets control method - claim system}

Up to $85 \%$ of total assets, the fixed asset management plays a significant role in the operation of grid corporations. For existing fixed assets, the claim system is a sensible choice, and it is a certain way to identify their real value and clarify the responsibility of corresponding departments. Specifically, each department claim necessary fixed assets in the classification of production equipment with power production management system, production equipment without power production management system, and non-production equipment. Comparing the difference between existing assets and claim assets, each department can determine the capital occupancy and utilization efficiency, and then the un-claim capital with proper depreciation rate is the measured impact on EVA.

\subsubsection{The behavior value decision method of capital structure}

Capital structure determines the capital cost, directly impacting on the EVA. Optimal design of capital structure should balance development and efficiency, comprehensively considering VBM factors. Considering the debt structure, liquidity, capital cost and financial leverage, it can be found the existing problems of grid corporations in capital structure [5].

\subsection{The behavior value decision method affecting the future EVA only}

In terms of issues affecting the future growth value, the grid corporations target at fixed assets investment (including project management under construction) in four stages: feasibility study, construction, operation and economic benefit evaluation.

\subsubsection{Behavior value analysis of feasibility study}

By studying the investment behavior of grid corporations, we notice that the value consideration in project establishment is not comprehensive enough, without showing value contribution from certain project. In the existing feasibility study report, the management simply focuses on the process input of construction, while ignoring the feasibility of setting standards and the analysis of the value contribution.

1) The project increasing the economic return 
For projects with better economic return, the expected increasing electricity sales and corresponding revenue are quantifiable. Based upon the EVA formula, the expected EVA can be calculated with the capital occupied of fixed assets. According to the expected effective years, the sum of discounted EVA for each period is the quantifiable value of fixed asset invested. As the formula below:

$$
V(X)=\sum_{i=1}^{n}\left\{\left[\left(R-C_{1}-C_{2} \cdots C_{m}\right)-T C_{1} \times W A C C_{1}\right] /(1+r)^{n}\right\}
$$

$V(X)$ : the contribution value of project $X$;

$R:$ the expected sales revenue;

$\mathrm{C}_{1} \cdots \mathrm{C}_{\mathrm{m}}:$ the cost of the project $X$ incurred in each period;

$r$ : the discount rate of EVA;

$n$ : the expected effective years

2) The project controlling the risk

The expected return is measured and calculated by the method of combining the EVA calculation with the probability distribution. Due to the uncertainties in reduction of risk and loss of fixed assets investment, the probability distribution of the expected EVA occurrence needs to be recalculated for precise prediction. Based on the expected utility theory, the expected EVA value is discounted as random variable $X$, and the probability value, $i=1,2,3 \ldots n$, is set according to the expected operation condition of the investment project... $\mathrm{N}$, the expected value of the random variable (EVA) is calculated based on the expected EVA value of the probability determined:

$$
U(X)=\sum_{i=0}^{n}[u(X N)]=P_{1} u\left(x_{1}\right)+P_{2} u\left(x_{2}\right)+P_{3} u\left(x_{3}\right)+\cdots+P_{n} u\left(x_{n}\right)
$$

$U(X)$ : the expected contribution value of project $X$

3) The project improving the management level

It is difficult to measure the value of project improving the management level mathematically. The reasons are: Firstly, they cannot directly make contribution to the growth in economic benefits. In the actual production process, the improvement on management level from such project can hardly be quantified by the economic benefits, and companies have less desire to collect and process the relevant information.

\subsubsection{Behavior value analysis of construction}

\section{1) Duration management}

Extension of time will inevitably lead to additional costs, and the assets under construction do not produce value. It delays the output of future EVA, negative with EVA. It is necessary to set a clear requirement of duration during the feasibility study, and strongly follow the schedule under construction.

2) Cost control

Cost and expense is the incremental items of capital invested, negative with EVA. These aspects should be considered: pre-project cost calculation, cost carry-over monthly and project settlement. As the main control factor, cost management plays a significant role throughout the power grid project.

3) Quality control

There is a close interdependence of construction cost and quality level. The quality cost consists of control cost and failure cost. Control cost belongs to the quality assurance fee, proportional to the level of quality. While failure cost is simply loss, negative with the level quality. The quality goal should be reasonable determined with the standard of project contracts. 
When project goes into operation, it will create value and the value-creating ability reflects the scale structure of capital invested and its sustainable development. Based on the classification of investment projects, and the uncontrollably macro factors, the management should target at the enhancement of profitability, risk control ability, and asset management capability, through streamline, life-cycling and intensification.

\subsubsection{Behavior value analysis of evaluation}

Although there is already an project evaluation system, it is not comprehensive enough because the feasibility study has not closely attached to the value target indicators. In terms of the evaluation, together with stages analyzed above, the management should pay more attention to the project's impact on the future growth value of grid corporations, and the difference between the expected contribution value and the actual one.

\section{Conclusion}

The enterprise value-creation results from the enterprise behavior based on specific markets and resources background. Generally, the enterprise behavior consist of production, sales, cost management, asset management, capital cost management and so on. In terms of different value drivers, the enterprise behavior, or business activities, are reclassified. This paper considers that, due to the different impact on the current and future EVA, the enterprise behavior can be divided into three categories: behaviors only affecting the current EVA, behaviors affecting both the current and future EVA, and behaviors only affecting the future EVA. The enterprise should establish a set of behavior control system targeting at sustainable EVA growth. The system can clarify the value contribution of the management and the staff respectively to the enterprise, check whether the decision-making deviates from the VBM target, and guide the direction of corporate behavior. Based on this, this paper has built a behavior vale analysis and decision methodology for gird corporations, including ones affecting the current, the future and both periods EVA.

\section{References}

1. Gang Wang. The Application of EVA Model in Grid Company.Friends of Accounting, 2008(5):106-107. (In Chinese)

2. SASAC. The Guidance on the improvement of Central SOEs' Value Management based on EVA. (In Chinese)

3. Martin J D, William Petty J. Value Based Management: The Corporate Response to the Shareholder Revolution. OUP Catalogue, 2001.

4. Zhenjin Zhao, Yuxin Di. The Application of EVA in the Investment Evaluation of Chinese companies. Contemporary Economic Research, 2005(4):43-47 (In Chinese)

5. Xin Xiao. The Research on EVA and the improvement. Northwest University, 2010. (In Chinese) 